\title{
Correction to: Imagining handwriting movements in a usual or unusual position: effect of posture congruency on visual and kinesthetic motor imagery
}

\author{
Jessica Guilbert ${ }^{1}\left[\mathbb{D} \cdot\right.$ Jonathan Fernandez $^{1} \cdot$ Michèle Molina $^{2} \cdot$ Marie-France Morin $^{3} \cdot$ Denis Alamargot $^{1}$
}

Published online: 25 March 2021

๑) Springer-Verlag GmbH Germany, part of Springer Nature 2021

\section{Correction to: Psychological Research https://doi.org/10.1007/s00426-020-01399-w}

In the original publication of the article, the affiliation of the author "Denis Alamargot" was numbered incorrectly.

The correct affiliation is "Univ Paris Est Creteil, UPL Univ Paris 8, EPHE PSL University, CHArt, 94,380 Bonneuil, France" which corresponds to number 1 but not 2 .

The original article has been updated.

Publisher's Note Springer Nature remains neutral with regard to jurisdictional claims in published maps and institutional affiliations.

The original article can be found online at https://doi.org/10.1007/ s00426-020-01399-w.

Jessica Guilbert

jessica.guilbert@u-pec.fr

1 Univ Paris Est Creteil, UPL Univ Paris 8, EPHE PSL

University, CHArt, 94380 Bonneuil, France

2 Université de Caen Normandie, LPCN (EA7452), MRSH, 14000 Caen, France

3 Université de Sherbrooke, Faculté d'Education, GRISE, Sherbrooke, Québec, Canada 